$\mathrm{NdFeB}$ 자석 스크랩을 이용한 $\mathrm{Mg}-\mathrm{Cu}-\mathrm{Gd}-\mathrm{Nd}$ 비정질 합금의 제조 및 특성

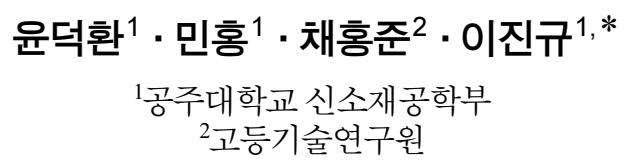

\title{
Formation and Characterization of Mg-Cu-Gd-Nd Bulk Metallic Glass Using NdFeB Magnet Scrap
}

\author{
Duck Hwan Yoon ${ }^{1}$, Hong Min ${ }^{1}$, Hong jun $\mathrm{Chae}^{2}$, and Jin Kyu Lee ${ }^{1, *}$ \\ ${ }^{\prime}$ Division of Advanced Materials Engineering, Kongju National University, Cheonan 31080, Republic of Korea \\ ${ }^{2}$ Institute for Advanced Engineering, Yongin 17180, Republic of Korea
}

\begin{abstract}
In the present study, new Mg-based bulk metallic glasses have been developed in a Mg-Cu-Gd$\mathrm{Nd}$ based system using a Mg-Nd byproduct obtained from the recycling process of $\mathrm{NdFeB}$ magnet scrap through liquid metal extraction. The $\mathrm{Mg}$-Cu-Gd-Nd bulk metallic glasses with a diameter of $2 \mathrm{~mm}$ are fabricated by injection casting using $\mathrm{Mg}$-Nd byproduct. The compressive fracture strength and total strain are $850 \mathrm{MPa}$ and $1.8 \%$, respectively, for the $\mathrm{Mg}_{66.5-\mathrm{x}} \mathrm{Cu}_{28.5} \mathrm{Gd}_{\mathrm{x}} \mathrm{Nd}_{5}(\mathrm{x}=8,10$ at\%) bulk metallic glasses. The activation energy of the $\mathrm{Mg}_{56.5} \mathrm{Cu}_{28.5} \mathrm{Gd}_{10} \mathrm{Nd}_{5}$ bulk metallic glass using $\mathrm{Mg}$-Nd byproduct is similar to that of conventional $\mathrm{Mg}_{56.5} \mathrm{Cu}_{28.5} \mathrm{Gd}_{10} \mathrm{Nd}_{5}$ bulk metallic glass using pure elements, indicating that the thermal stability in the supercooled liquid region is similar. From the results, the recycling process for $\mathrm{NdFeB}$ magnet scrap can be considered a cost effective method for the formation of Mg-based bulk metallic glasses. It can therefore be concluded that the newly developed $\mathrm{Mg}-\mathrm{Cu}-\mathrm{Gd}-\mathrm{Nd}$ bulk metallic glasses using $\mathrm{Mg}-\mathrm{Nd}$ byproduct obtained from the recycling process of $\mathrm{NdFeB}$ magnet scrap have potential for industrial application.
\end{abstract}

(Received July 31, 2019; Accepted August 27, 2019)

Keywords: Mg, bulk metallic glass, NdFeB, recycling, scrap

\section{1. 서 론}

$\mathrm{NdFeB}$ 자석의 최대자기 에너지적, 전류자속 밀도, 보자 력 등의 자성 특성은 현존하는 영구자석 중 가장 우수한 것으로 알려져 있으며. 이러한 우수한 자성 특성으로 인해 자동차, 전자 등 주요 산업에 폭 넓게 활용이 되고 있다. $\mathrm{NdFeB}$ 자석의 수요는 2000년대 초반까지 주로 정보저장 매체나 가전기기용의 용도가 주요 시장이었고, 최근 들어 친환경 자동차인 하이브리드 및 전기자동차 산업의 발전과 신재생에너지인 풍력산업의 수요 증가에 따라 고기능성 모 터의 핵심소재로 사용되는 $\mathrm{NdFeB}$ 자석의 수요가 증가하 고 있다. $\mathrm{NdFeB}$ 자석의 주요 원소인 $\mathrm{Nd}$ 과 보자력을 높

- 윤덕환 · 민홍: 석사과정, 채홍준: 연구원, 이진규: 교수

*Corresponding Author: Jin Kyu Lee

[Tel: +82-41-521-9388, E-mail: jklee71@kongju.ac.kr]

Copyright (c) The Korean Institute of Metals and Materials
이기 위해 소량 포함되는 Dy과 같은 희토류 원소는 적은 매장량으로 인해 최근 수급 불균형의 문제가 발생하고 있 으므로 안정적인 원소의 공급이 중요한 화두로 떠오르고 있다. 또한 $\mathrm{NdFeB}$ 소결 자석의 경우 성형, 소결, 가공 과 정에서 스크랩이 원료의 $30 \%$ 이상 발생하는 것으로 알려 져 있다. 특히 국내의 경우 $\mathrm{NdFeB}$ 소결 자석은 전량 수 입에 의존하고 있으며, 발생하는 스크랩은 재활용되지 못 하고 해외로 수출되는 것으로 알려져 있다 [1].

기존의 $\mathrm{NdFeB}$ 소결 자석 스크랩의 재활용 방법으로 전 통적인 습식야금 기술을 이용하여 분쇄된 자석 스크랩을 산을 이용하여 용해하고, 용해된 액상을 침전하고 분리하 여 $\mathrm{Nd}$ 을 얻는 공정이 제시되었다 [2-4]. 최근에는 $\mathrm{NdFeB}$ 스크랩을 $\mathrm{Mg}$ 용탕에 침지하여 자석 스크랩내의 $\mathrm{Nd}$ 을 $\mathrm{Mg}$ 용탕 내부로 확산시킨 후 고액 분리 반응으로 이용하여 $\mathrm{Nd}$ 이 함유된 $\mathrm{Mg}$ 액상을 얻고, 최종적으로는 $\mathrm{Mg}$ 을 기화 시켜 $\mathrm{Nd}$ 을 얻는 방안이 제시되었다 [5-8]. 이러한 $\mathrm{Mg}$ 용 
탕을 이용한 $\mathrm{NdFeB}$ 자석의 재활용 방법은 건식 반응으로 습식반응과 같이 유해한 화학 물질이 필요하지 않고, 반응 공정이 비교적 단순하다는 장점이 있다.

최근 많은 연구가 이루어지고 있는 고온 기계적 특성이 우수한 $\mathrm{Mg}$ 합금은 $\mathrm{Nd}$ 과 같은 희토류(rare earth, $\mathrm{RE}$ ) 원 소가 함유되어 있다 $[9,10] . \mathrm{Mg}-\mathrm{Nd}-\mathrm{Zn}-\mathrm{Zr}$ 합금의 경우 $\mathrm{Nd}$ 은 석출 강화 효과를 증진시키고 [11], Mg-Nd 합금의 경 우 석출 입자들이 전위이동을 억제하여 크리프 저항성을 증가시키는 것으로 보고되었다 [12]. 또한 $\mathrm{Mg}$ 계 벌크 비 정질 합금의 경우에도 $\mathrm{Nd}$ 을 첨가하여 비정질 형성능을 향 상시킨 결과가 $\mathrm{Mg}-\mathrm{Ni}-\mathrm{Nd}$ 및 $\mathrm{Mg}-\mathrm{Cu}-(\mathrm{Y}, \mathrm{Nd})$ 합금계 등 에서 보고되었다 $[13,14]$. 그러나 우수한 특성을 가지는 $\mathrm{Mg}$ 합금을 제조하기 위해 $\mathrm{Nd}$ 와 같은 고가의 희토류 순금 속을 사용하는 것은 경제적인 부분에서는 단점이 되고 있 다. $\mathrm{Mg}$ 용탕을 이용한 $\mathrm{NdFeB}$ 자석 스크랩의 재활용 방 법의 경우 중간 단계에서 $\mathrm{Nd}$ 을 함유한 $\mathrm{Mg}$ 용탕이 얻어지 고, 고액 분리 반응에 의해 $\mathrm{Nd}$ 이 함유된 $\mathrm{Mg}$ 합금을 얻을 수 있으므로 $[15,16]$, 이러한 $\mathrm{Nd}$ 함유 $\mathrm{Mg}$ 합금을 $\mathrm{Nd}$ 을 포함하는 $\mathrm{Mg}$ 합금 제조에 활용할 수 있다면 $\mathrm{NdFeB}$ 자석 스크랩의 재활용 및 $\mathrm{Mg}$ 합금의 상용화 측면에서 경제적인 순환 소재 공정 및 제조 기술이 될 수 있다.

본 연구에서는 $\mathrm{NdFeB}$ 자석 스크랩의 순환 소재화 공정 에서 얻어지는 $\mathrm{Mg}-\mathrm{Nd}$ 합금을 이용하여 새로운 $\mathrm{Mg}$ 계 벌 크 비정질 합금을 제조하고 그 특성을 평가하고자 하였다. 이를 통하여 궁극적으로는 $\mathrm{NdFeB}$ 자석의 순환소재화 공 정의 사례를 제시하고, 희토류를 포함하는 $\mathrm{Mg}$ 벌크 비정 질 재료의 새로운 제조 공정을 제시하고자 한다.

\section{2. 실험방법}

그림 1 은 $\mathrm{Mg}$ 용탕을 이용하여 $\mathrm{NdFeB}$ 자석 스크랩으로 부터 $\mathrm{Nd}$ 을 추출하는 공정의 모식도를 보여주고 있다 [5]. 공정 온도에서 $\mathrm{Mg}$ 에 대하여 $\mathrm{Nd}$ 은 충분한 고용도를 가지 는 반면 $\mathrm{Fe}$ 와 $\mathrm{B}$ 는 극히 낮은 용해도를 가지므로 $\mathrm{NdFeB}$

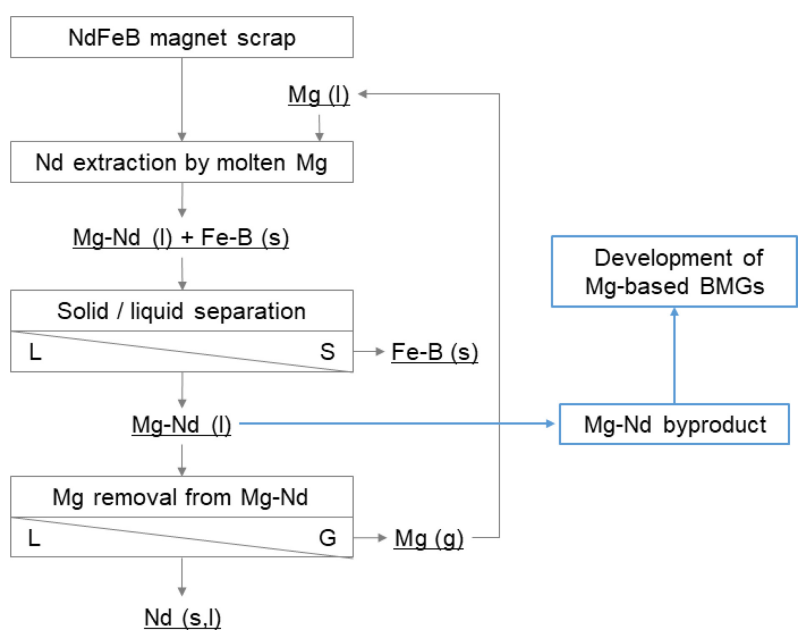

Fig. 1. Process for $\mathrm{Nd}$ extraction from $\mathrm{Nd}-\mathrm{Fe}-\mathrm{B}$ magnet scrap by $\mathrm{Mg}$.

자석내의 $\mathrm{Nd}$ 은 용탕내로 확산하게 되고, $\mathrm{Fe}$ 와 $\mathrm{B}$ 는 고상 상태로 잔류하게 된다. $\mathrm{Nd}$ 을 포함하는 액상 $\mathrm{Mg}$ 과 고상 $\mathrm{Fe}-\mathrm{B}$ 를 고액 분리하게 되면 액상의 $\mathrm{Mg}-\mathrm{Nd}$ 와 고상의 $\mathrm{Fe}-$ $\mathrm{B}$ 를 얻을 수 있으며, $\mathrm{Mg}-\mathrm{Nd}$ 액상으로부터 $\mathrm{Mg}$ 을 기화시 켜 $\mathrm{Nd}$ 를 얻을 수 있고, 고상의 $\mathrm{Fe}-\mathrm{B}$ 은 철강용 소재로 활 용될 수 있다 $[5,6]$.

본 연구에서는 고액 분리에 의해 얻어지는 $\mathrm{Mg}-\mathrm{Nd}$ 액상 을 모합금으로 활용하여 $\mathrm{Mg}$ 계 비정질 합금 제조에 활용하 고자 하였다. $\mathrm{Mg}$ 용탕에 상용 $\mathrm{NdFeB}$ 자석 스크랩을 넣 은 후 $1073 \mathrm{~K}$ 에서 60 분 동안 반응시킨 후 고액 분리하여 $\mathrm{Mg}-\mathrm{Nd}$ 모합금을 제조하였다. 표 1은 본 연구에서 사용한 $\mathrm{NdFeB}$ 자석(Grade N35) 스크랩의 유도결합 플라즈마 분 광 분석(ICP, ICPA-6300 Duo, Thermo Scientific) 결과 를 보여주고 있다. 표 2 는 $\mathrm{Mg}$ 용탕 추출법으로 제조된 $\mathrm{Mg}-\mathrm{Nd}$ 모합금의 유도결합 플라즈마 분광 분석 결과를 보 여주고 있으며, $\mathrm{Nd}$ 이외에도 $\mathrm{Gd}$ 과 $\mathrm{Pr}$ 이 소량 포함되어 있는 것을 알 수 있다.

제조된 $\mathrm{Mg}-\mathrm{Nd}$ 모합금과 $\mathrm{Mg}(99.9 \%), \mathrm{Cu}(99.9 \%)$, $\mathrm{Nd}(99.9 \%), \mathrm{Gd}(99.9 \%)$ 의 원소를 혼합하여 고주파 유도

Table 1. Overall composition of NdFeB magnet scrap (Grade N35) by ICP analysis

\begin{tabular}{cccccccc}
\hline Element & $\mathrm{Fe}$ & $\mathrm{Nd}$ & $\mathrm{Gd}$ & $\mathrm{Pr}$ & $\mathrm{B}$ & $\mathrm{Al}$ & $\mathrm{Nb}$ \\
\hline$(\mathrm{wt} \%)$ & 72.06 & 17.95 & 6.66 & 3.88 & 0.96 & 0.90 & 0.14 \\
\hline
\end{tabular}

Table 2. Overall composition of Mg-Nd byproduct obtained from the recycling process of NdFeB magnet scrap through liquid metal extraction by ICP analysis

\begin{tabular}{ccccccccc}
\hline Element & $\mathrm{Mg}$ & $\mathrm{Nd}$ & $\mathrm{Gd}$ & $\mathrm{Pr}$ & $\mathrm{Al}$ & $\mathrm{Fe}$ & $\mathrm{Nb}$ & $\mathrm{B}$ \\
\hline$(\mathrm{wt} \%)$ & 79.34 & 12.54 & 3.6 & 3.83 & 0.32 & 0.21 & 0.07 & 0.06 \\
\hline
\end{tabular}


용해로를 이용하여 고순도의 $\operatorname{Ar}(99.999 \%)$ 분위기 하에서 용해하여 $\mathrm{Mg}-\mathrm{Cu}-\mathrm{Gd}-\mathrm{Nd}$ 합금을 제조하였다. 제조된 $\mathrm{Mg}$ $\mathrm{Cu}-\mathrm{Gd}-\mathrm{Nd}$ 합금을 injection casting법을 이용하여 구리 몰 드에 주조하여 지름이 $2 \mathrm{~mm}$ 인 봉상 형태의 비정질 합금 을 제조하였다. 제조된 비정질 시편의 구조 분석을 위하여 X-선 회절(XRD, MiniFlex600, Rigaku)을 행하였고, $\mathrm{CuK} \alpha_{1}(\lambda=1.5406 \AA)$ 을 이용하여 연속주사 방법으로 $20^{\circ} \sim 80^{\circ}$ 의 범위에서 $4 \% \mathrm{~min}$ 의 주사속도로 회절 도형을 얻 었다. 비정질 합금의 유리천이 온도(glass transition temperature, $\mathrm{T}_{\mathrm{g}}$ ), 결정화 온도(crystallization temperature, $\mathrm{Tx}$ ) 및 결정화 엔탈피(crystallization enthalpy, $\Delta \mathrm{H}$ )는 시 차 열분석기(DSC, DSC8000, PerkinElmer)을 이용하여 $373 \sim 623 \mathrm{~K}$ 의 범위에서 고순도( $99.999 \%)$ 의 $\mathrm{Ar}$ 분위기에서 $20 \mathrm{~K} / \mathrm{min}$ 의 속도로 승온하면서 측정하였다. 제조된 시편의 기계적 특성은 만능시험기(UTM, AG-X, SHIMADZU)를 이용하여 압축강도를 측정하였으며, 상온에서 $1 \times 10^{-4} \mathrm{~s}^{-1}$ 의 변형속도로 실시하였다. 강도 시험 후 파단면은 주사전자 현미경(SEM, MIRA LMH, TESCAN)을 이용하여 관찰하 였다.

\section{3. 실험 결과}

본 연구에서 사용한 상용 $\mathrm{NdFeB}$ 자석 스크랩으로부터 얻어지는 $\mathrm{Mg}-\mathrm{Nd}$ 모합금은 성분 분석결과 $\mathrm{Nd}$ 이외에도 $\mathrm{Gd}$ 과 $\mathrm{Pr}$ 을 일부 포함하고 있으므로, 본 연구에서는 $\mathrm{Nd}$ 과 $\mathrm{Gd}$ 을 포함하는 $\mathrm{Mg}-\mathrm{Cu}-\mathrm{Gd}-\mathrm{Nd}$ 비정질 합금계를 설계하였 으며, 상대적으로 소량 포함되는 $\mathrm{Pr}$ 은 $\mathrm{Mg}$ 원소 조성에 포 함하여 합금 설계를 진행하였다.

그림 2는 injection casting에 의해 제조된 직경 $2 \mathrm{~mm}$ 의 $\mathrm{Mg}_{66.5-\mathrm{x}} \mathrm{Cu}_{28.5} \mathrm{Gd}_{\mathrm{x}} \mathrm{Nd}_{5}(\mathrm{x}=4,6,8,10 \mathrm{at} \%)$ 벌크 비정질 합 금의 $\mathrm{X}$-선 회절도형을 나타내고 있으며, 비정질 상에서 나 타나는 전형적인 halo pattern을 보여주고 있다.

그림 3은 제조된 $\mathrm{Mg}_{66.5-\mathrm{x}} \mathrm{Cu}_{28.5} \mathrm{Gd}_{\mathrm{x}} \mathrm{Nd}_{5}(\mathrm{x}=4,6,8,10$ $\mathrm{at} \%$ ) 벌크 비정질 합금을 $20 \mathrm{~K} / \mathrm{min}$ 의 속도로 가열하면서 얻은 시차열분석 결과로서, 비정질상은 유리천이 온도 $\mathrm{T}_{\mathrm{g}}$ 에서 유리 천이가 일어나 과냉각 액상영역을 거쳐서 결정 화 온도 $\mathrm{T}_{\mathrm{x}}$ 에서 결정상으로 상변화가 일어나는 것을 알 수 있다. $\mathrm{Gd}$ 의 함량이 증가함에 따라 유리천이 온도 $\mathrm{T}_{\mathrm{g}}$ 와 비 정질 합금의 열적 안정성을 나타내는 결정화 온도 $\mathrm{T}_{\mathrm{x}}$ 는 증 가하는 것을 알 수 있으며, 과냉각 액상영역 $\left(\Delta \mathrm{T}_{\mathrm{x}}=\mathrm{T}_{\mathrm{x}}-\mathrm{T}_{\mathrm{g}}\right)$ 은 $\mathrm{Mg}_{62.5} \mathrm{Cu}_{28.5} \mathrm{Gd}_{4} \mathrm{Nd}_{5}$ 비정질 합금의 경우 가장 큰 $56 \mathrm{~K}$ 의 값을 나타내었다. 또한 $\mathrm{Mg}_{56.5} \mathrm{Cu}_{28.5} \mathrm{Gd}_{10} \mathrm{Nd}_{5}$ 비정질 합금의 경우는 두 개의 겹쳐진 발열 피크를 보여주고 있고, 나머

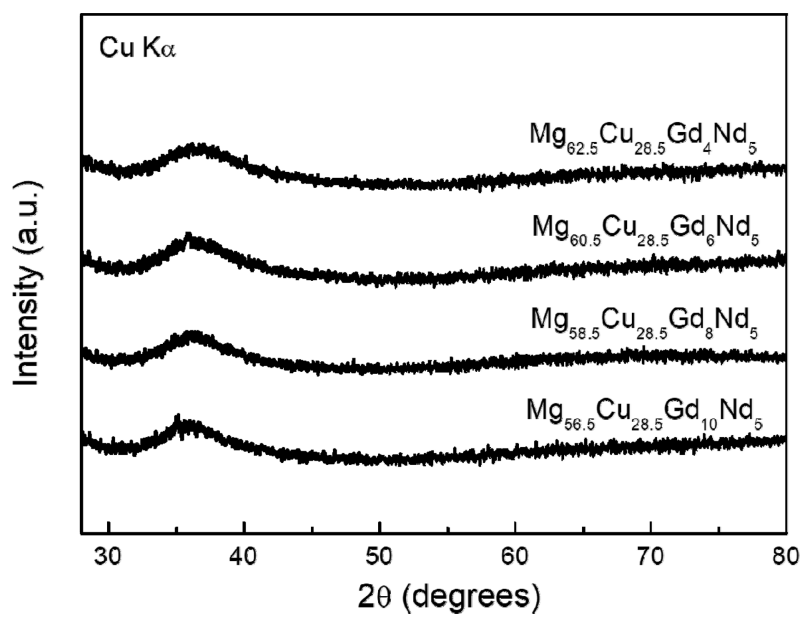

Fig. 2. XRD traces obtained from the $\mathrm{Mg}_{66.5-\mathrm{x}} \mathrm{Cu}_{28.5} \mathrm{Gd}_{\mathrm{x}} \mathrm{Nd}_{5}(\mathrm{x}=4,6$, 8,10 at $\%$ ) bulk metallic glasses.

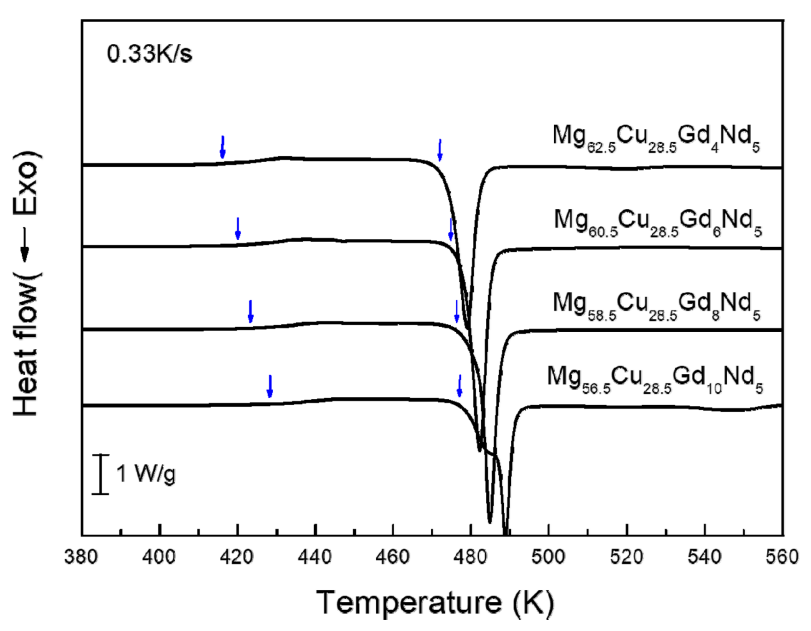

Fig. 3. DSC curves obtained from the $\mathrm{Mg}_{66.5-\mathrm{x}} \mathrm{Cu}_{28.5} \mathrm{Gd}_{\mathrm{x}} \mathrm{Nd}_{5}(\mathrm{x}=4,6$, 8,10 at $\%$ ) bulk metallic glasses.

Table 3. Thermal properties of $\mathrm{Mg}_{66.5-\mathrm{x}} \mathrm{Cu}_{28.5} \mathrm{Gd}_{\mathrm{x}} \mathrm{Nd}_{5}(\mathrm{x}=4,6,8,10$ at $\%$ ) bulk metallic glasses by DSC analysis

\begin{tabular}{ccccc}
\hline & $\mathrm{T}_{\mathrm{g}}(\mathrm{K})$ & $\mathrm{T}_{\mathrm{x}}(\mathrm{K})$ & $\Delta \mathrm{T}_{\mathrm{x}}(\mathrm{K})$ & $\Delta \mathrm{H}(\mathrm{J} / \mathrm{g})$ \\
\hline $\mathrm{Mg}_{62.5} \mathrm{Cu}_{28.5} \mathrm{Gd}_{4} \mathrm{Nd}_{5}$ & 416 & 472 & 56 & 51.2 \\
\hline $\mathrm{Mg}_{60.5} \mathrm{Cu}_{28.5} \mathrm{Gd}_{6} \mathrm{Nd}_{5}$ & 420 & 475 & 55 & 60.7 \\
\hline $\mathrm{Mg}_{58.5} \mathrm{Cu}_{28.5} \mathrm{Gd}_{8} \mathrm{Nd}_{5}$ & 423 & 476 & 53 & 68.2 \\
\hline $\mathrm{Mg}_{56.5} \mathrm{Cu}_{28.5} \mathrm{Gd}_{10} \mathrm{Nd}_{5}$ & 428 & 477 & 49 & 62.5 \\
\hline
\end{tabular}

지 비정질 합금들의 경우는 하나의 발열 피크를 보여주고 있다. 표 3은 제조된 $\mathrm{Mg}_{66.5-\mathrm{x}} \mathrm{Cu}_{28.5} \mathrm{Gd}_{\mathrm{x}} \mathrm{Nd}_{5}(\mathrm{x}=4,6,8,10$ $\mathrm{at} \%$ ) 벌크 비정질 합금에서 얻어진 열분석 결과를 보여주 고 있다.

제조된 벌크 비정질 합금의 기계적 특성을 평가하기 위해 서 상온에서 압축강도 시험을 실시하였다. 그림 4는 injection 


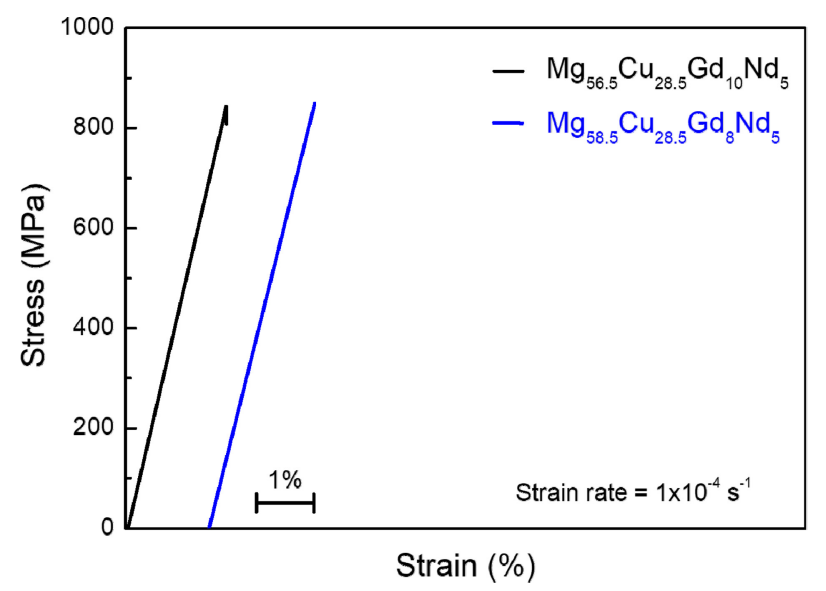

Fig. 4. Compressive stress-strain curves of the $\mathrm{Mg}_{58.5} \mathrm{Cu}_{28.5} \mathrm{Gd}_{8} \mathrm{Nd}_{5}$ and $\mathrm{Mg}_{56.5} \mathrm{Cu}_{28.5} \mathrm{Gd}_{10} \mathrm{Nd}_{5}$ bulk metallic glasses.

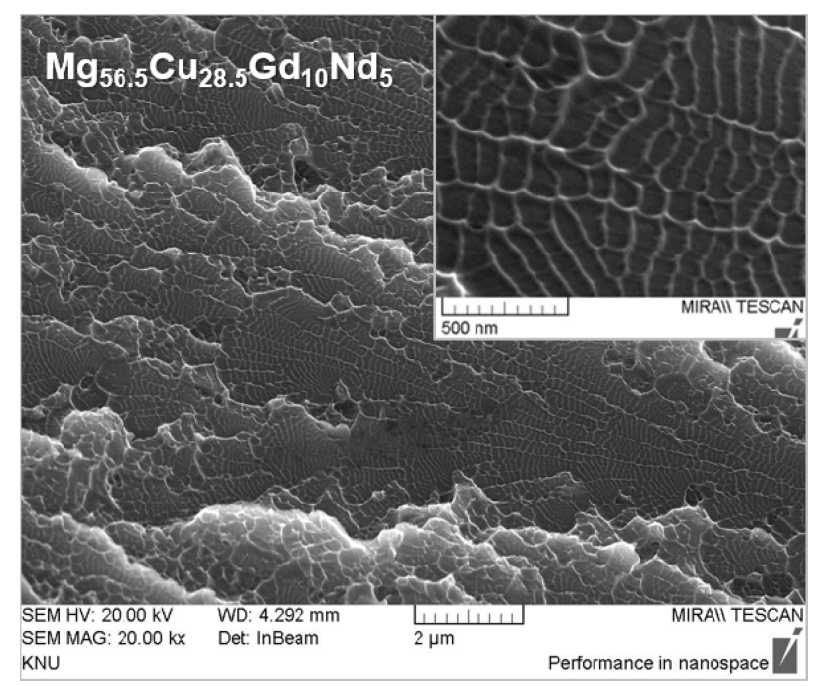

Fig. 5. Fracture surface of $\mathrm{Mg}_{56.5} \mathrm{Cu}_{28.5} \mathrm{Gd}_{10} \mathrm{Nd}_{5}$ bulk metallic glass.

casting으로 제조된 $\mathrm{Mg}_{58.5} \mathrm{Cu}_{28.5} \mathrm{Gd}_{8} \mathrm{Nd}_{5}$ 과 $\mathrm{Mg}_{56.5} \mathrm{Cu}_{28.5} \mathrm{Gd}_{10} \mathrm{Nd}_{5}$ 벌크 비정질 합금의 압축시험 결과를 보여주고 있다. 두 합 금은 모두 약 $850 \mathrm{MPa}$ 의 파단압축강도(fracture strength, $\sigma_{\mathrm{f}}$ )와 $1.8 \%$ 의 총 연신율(total strain, $\left.\varepsilon_{\mathrm{f}}\right)$ 을 나타내고 있고, 기존에 보고된 $\mathrm{Mg}_{65} \mathrm{Cu}_{25} \mathrm{Gd}_{10}$ 벌크 비정질 합금의 $650 \mathrm{MPa}$ 의 파단압축강도와 비교하여 $200 \mathrm{MPa}$ 정도의 높은 값을 나 타내었다 [17]. 그림 5 는 $\mathrm{Mg}_{56.5} \mathrm{Cu}_{28.5} \mathrm{Gd}_{10} \mathrm{Nd}_{5}$ 벌크 비정질 합금의 압축강도 시험 후 파단면의 형상을 보여주고 있으 며. 비정질 합금의 전형적인 vein-like pattern을 보여주고 있다. 이러한 vein-like pattern은 일축 하중에서 변형이 일 어날 때 시편 내부에서 국부적인 열의 발생과 자유부피의 증가로 인해 점성이 낮아져 불균일 변형이 일어나면서 형 성되는 것으로 보고되고 있다 [18-20].
Table 4. DSC results obtained from the $\mathrm{Mg}_{56.5} \mathrm{Cu}_{28.5} \mathrm{Gd}_{10} \mathrm{Nd}_{5}$ bulk metallic glasses using $\mathrm{Mg}-\mathrm{Nd}$ byproduct and using pure elements at different heating rates.

\begin{tabular}{ccc}
\hline \multirow{2}{*}{$\begin{array}{c}\text { Heating rate } \\
(\mathrm{K} / \mathrm{min})\end{array}$} & \multicolumn{2}{c}{ Peak temperature, $\mathrm{T}_{\mathrm{p}}(\mathrm{K})$} \\
\cline { 2 - 3 } & $\begin{array}{c}\text { Using } \\
\text { pure elements }\end{array}$ & $\begin{array}{c}\text { Using Mg-Nd } \\
\text { byproduct }\end{array}$ \\
\hline 10 & 479 & 481 \\
\hline 20 & 486 & 489 \\
\hline 40 & 496 & 497 \\
\hline
\end{tabular}

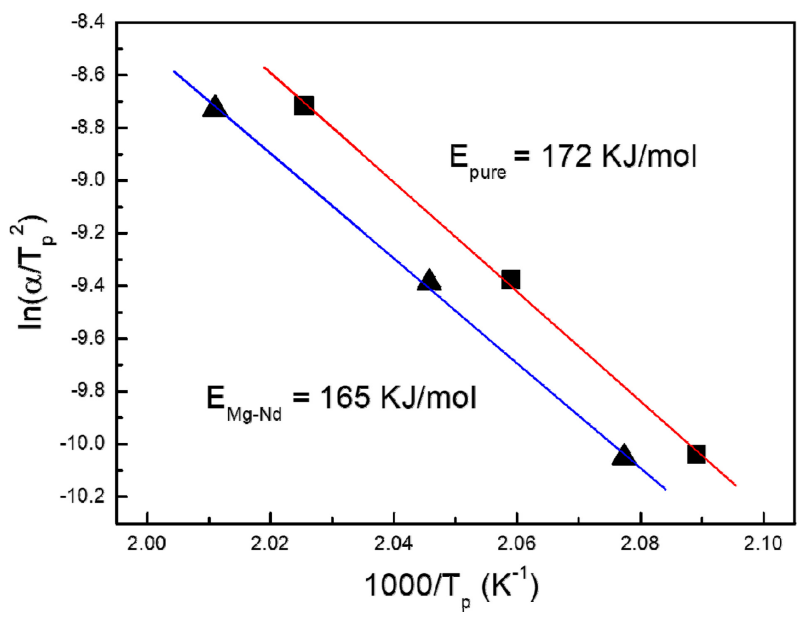

Fig. 6. Kissinger plots of the $\mathrm{Mg}_{56.5} \mathrm{Cu}_{28.5} \mathrm{Gd}_{10} \mathrm{Nd}_{5}$ bulk metallic glasses using $\mathrm{Mg}-\mathrm{Nd}$ byproduct and using pure elements.

상용 $\mathrm{NdFeB}$ 자석 스크랩으로부터 얻어지는 $\mathrm{Mg}-\mathrm{Nd}$ 모 합금을 활용하여 제조된 $\mathrm{Mg}-\mathrm{Cu}-\mathrm{Gd}-\mathrm{Nd}$ 벌크 비정질 합금 과 순수한 원소를 이용하여 제조된 $\mathrm{Mg}-\mathrm{Cu}-\mathrm{Gd}-\mathrm{Nd}$ 벌크 비정질 합금의 열적 안정성을 비교하기 위해서 Kissinger 식을 이용하였다. Kissinger 식은 비정질 합금의 결정화 반 응에 대한 활성화 에너지를 얻기 위해 많이 활용되고 있으 며 [21], 관계식은 다음과 같다.

$$
\ln \left(\frac{\alpha}{T_{p}^{2}}\right)=\frac{E}{R T}+C
$$

이 식에서 $\mathrm{T}_{\mathrm{p}}$ 는 결정화 발열피크 온도 $(\mathrm{K}), \alpha$ 는 시차열분 석에서의 승온 속도 $(\mathrm{K} / \mathrm{s}), \mathrm{R}$ 은 기체상수 $(8.314 \mathrm{~J} / \mathrm{K} \cdot \mathrm{mol})$ 를 의미한다. 표 4 는 여러 승온 속도 $(10,20,40 \mathrm{~K} / \mathrm{min})$ 로 측정된 상용 $\mathrm{NdFeB}$ 자석 스크랩으로부터 얻어진 $\mathrm{Mg}-\mathrm{Nd}$ 모합금을 활용하여 제조된 $\mathrm{Mg}_{56.5} \mathrm{Cu}_{28.5} \mathrm{Gd}_{10} \mathrm{Nd}_{5}$ 벌크 비정질 합금과 순수한 원소를 이용하여 제조된 $\mathrm{Mg}_{56.5} \mathrm{Cu}_{28.5} \mathrm{Gd}_{10} \mathrm{Nd}_{5}$ 벌크 비정질 합금의 시차열분석 결과를 보여주고 있다. 표 4 에서 얻어진 각 합금의 결정화 피크 온도를 이용하여 $\ln \left(\alpha / T_{\mathrm{p}}{ }^{2}\right)$ 와 $1 / T_{\mathrm{p}}$ 의 Kissinger plot을 그림 6 에 나타내었으 
Table 5. Overall composition of $\mathrm{Mg}_{56.5} \mathrm{Cu}_{28.5} \mathrm{Gd}_{10} \mathrm{Nd}_{5}$ bulk metallic glass using Mg-Nd byproduct by ICP analysis

\begin{tabular}{ccccccccc}
\hline Element & $\mathrm{Mg}$ & $\mathrm{Cu}$ & $\mathrm{Gd}$ & $\mathrm{Nd}$ & $\mathrm{Pr}$ & $\mathrm{Al}$ & $\mathrm{Fe}$ \\
\hline$(\mathrm{at} \%)$ & 54.91 & 29.38 & 9.38 & 5.53 & 0.70 & 0.06 & 0.04 \\
\hline$(\mathrm{wt} \%)$ & 24.03 & 33.62 & 26.56 & 14.36 & 0.39 & 0.03 & 0.04
\end{tabular}

며, 이때 얻어진 값들을 선형 회귀하여 얻은 직선의 기울 기로부터 결정화에 대한 활성화 에너지를 계산하였다. 순 수한 원소를 이용하여 제조된 $\mathrm{Mg}_{56.5} \mathrm{Cu}_{28.5} \mathrm{Gd}_{10} \mathrm{Nd}_{5}$ 벌크 비 정질 합금의 활성화 에너지는 $172 \mathrm{KJ} / \mathrm{mol}$ 이며, $\mathrm{NdFeB}$ 자석 스크랩으로부터 얻어지는 $\mathrm{Mg}-\mathrm{Nd}$ 모합금을 활용하여 제조된 $\mathrm{Mg}_{56.5} \mathrm{Cu}_{28.5} \mathrm{Gd}_{10} \mathrm{Nd}_{5}$ 벌크 비정질 합금의 활성화 에너지는 $165 \mathrm{KJ} / \mathrm{mol}$ 로 계산되었다.

\section{4. 고 찰}

본 연구에서 비정질 합금 제조에 사용한 $\mathrm{NdFeB}$ 자석 스크랩으로부터 얻어진 $\mathrm{Mg}-\mathrm{Nd}$ 모합금은 $\mathrm{Nd}$ 와 $\mathrm{Gd}$ 을 포함 하고 있으므로, 두 원소를 포함하는 $\mathrm{Mg}$ 계 비정질 합금계 인 $\mathrm{Mg}-\mathrm{Cu}-\mathrm{Gd}-\mathrm{Nd}$ 합금계를 설계하였다. 일반적으로 우수 한 비정질 형성능을 갖기 위해서는, 3 개 이상의 원소를 포 함하는 다성분계 시스템과 구성 원소들 사이에 큰 음의 혼 합열(heat of mixing) 및 주요 구성 원소들 사이에 약 $12 \%$ 이상의 큰 원자반경 차이를 가져야 한다는 경험법칙 이 알려져 있다 [22]. 기존 연구에 의하면 이런 경우 액상 의 충진 밀도(packing density)가 높고, 낮은 온도까지 안 정한 상태로 유지하여 원자의 이동도가 감소하고, 결정상 의 핵생성이 억제되어 비정질 형성능이 향상되는 것으로 보고되었다 [22]. 본 연구에서 제안된 $\mathrm{Mg}-\mathrm{Cu}-\mathrm{Gd}-\mathrm{Nd}$ 합금 계의 경우, 기존에 보고된 $\mathrm{Mg}-\mathrm{Cu}-\mathrm{Gd}$ 3원계에 비해 4원계 다성분계 시스템을 기본으로 하고 있으며, $\mathrm{Gd}$ 과 $\mathrm{Nd}$ 은 상 태도상에서 서로 고용체를 이루고 있다. 또한 구성원소의 원자 반경은 $\mathrm{Mg} 1.6 \AA, \mathrm{Cu} 1.28 \AA, \mathrm{Gd} 1.8 \AA, \mathrm{Nd} 1.82$ $\AA$ 로 $\mathrm{Nd}$ 과 $\mathrm{Gd}$ 은 $\mathrm{Mg}$ 과는 약 $13 \%, \mathrm{Cu}$ 와는 약 $41 \%$ 의 큰 원자반경 차이를 가지고 있고, 구성 원소들 간의 혼합열은 $\mathrm{Mg}-\mathrm{Cu}-3 \mathrm{~kJ} / \mathrm{mol}, \mathrm{Mg}-\mathrm{Gd}-6 \mathrm{~kJ} / \mathrm{mol}, \mathrm{Mg}-\mathrm{Nd}-6 \mathrm{~kJ} / \mathrm{mol}$, $\mathrm{Cu}-\mathrm{Gd}-22 \mathrm{~kJ} / \mathrm{mol}, \mathrm{Cu}-\mathrm{Nd}-22 \mathrm{~kJ} / \mathrm{mol}$ 로 큰 음의 혼합열 을 가지는 것을 알 수 있으며, 이로부터 $\mathrm{Mg}-\mathrm{Cu}-\mathrm{Gd}-\mathrm{Nd}$ 합금 시스템은 비정질 형성능 향상을 위한 경험법칙을 모 두 충족시키는 것을 알 수 있다. 그러므로 기존 $\mathrm{Mg}-\mathrm{Cu}-$ $\mathrm{Gd}$ 합금계 대비 $\mathrm{Nd}$ 이 첨가된 $\mathrm{Mg}-\mathrm{Cu}-\mathrm{Gd}-\mathrm{Nd}$ 합금계는 액 상의 구조를 좀 더 조밀하게 만들어 액상내의 원자의 이동 도를 감소시키고, 그 결과 액상 내에서 핵생성과 결정상 성장을 위한 원자들의 재배열의 속도가 감소하여 결정상의
핵생성이 억제되어 비정질 형성능이 증가하는 것으로 판단 된다.

본 연구에서 사용한 $\mathrm{NdFeB}$ 자석 스크랩으로부터 얻어 지는 $\mathrm{Mg}-\mathrm{Nd}$ 모합금은 소량의 $\mathrm{Gd}, \mathrm{Pr}$ 과 극미량의 $\mathrm{Al}, \mathrm{Fe}$ 를 포함하고 있으므로, 이러한 $\mathrm{Mg}-\mathrm{Nd}$ 모합금을 이용하여 제조된 $\mathrm{Mg}-\mathrm{Cu}-\mathrm{Gd}-\mathrm{Nd}$ 합금 역시 소량의 $\mathrm{Pr}, \mathrm{Al}, \mathrm{Fe}$ 등의 원소를 포함하고 있을 것으로 판단되어, $\mathrm{Mg}-\mathrm{Nd}$ 모합금을 사용하여 제조된 벌크 비정질 합금에 대하여 유도결합 플 라즈마 분광 분석을 실시하였다. 표 5 는 $\mathrm{Mg}-\mathrm{Nd}$ 모합금을 사용하여 제조된 $\mathrm{Mg}_{56.5} \mathrm{Cu}_{28.5} \mathrm{Gd}_{10} \mathrm{Nd}_{5}$ 벌크 비정질 합금의 유도결합 플라즈마 분광 분석 결과를 보여주고 있으며, 제 조된 $\mathrm{Mg}_{56.5} \mathrm{Cu}_{28.5} \mathrm{Gd}_{10} \mathrm{Nd}_{5}$ 벌크 비정질 합금은 소량의 $\operatorname{Pr}$ 과 극미량의 $\mathrm{Al}, \mathrm{Fe}$ 원소를 포함하고 있음을 알 수 있다. 이 러한 결과로부터 $\mathrm{NdFeB}$ 자석 스크랩으로부터 얻어진 $\mathrm{Mg}$ $\mathrm{Nd}$ 모합금을 활용하여 제조된 $\mathrm{Mg}-\mathrm{Cu}-\mathrm{Gd}-\mathrm{Nd}$ 벌크 비정질 합금은 기존의 고순도의 원소만으로 제조된 벌크 비정질 합금과는 달리 스크랩에 함유되어 있는 미량 원소가 포함 되어도 비정질 형성이 가능함을 보여주고 있다. 제조된 $\mathrm{Mg}-\mathrm{Cu}-\mathrm{Gd}-\mathrm{Nd}$ 벌크 비정질 합금에 소량 포함된 $\mathrm{Pr}$ 원소 의 경우 원자반경은 $1.82 \AA$ 으로 $\mathrm{Mg}, \mathrm{Cu}$ 등의 주요 구성 원소와 $12 \%$ 이상의 원자 반경을 가지고 있으며, 혼합열의 경우 $\mathrm{Mg}$ 과는 $-6 \mathrm{~kJ} / \mathrm{mol}, \mathrm{Cu}$ 와는 $-22 \mathrm{~kJ} / \mathrm{mol}$ 의 음의 혼 합열을 가지는 것을 알 수 있다. 그러므로 이러한 소량의 $\operatorname{Pr}$ 의 첨가는 비정질 형성능 향상을 위한 경험 법칙을 충족 시키는 것을 알 수 있으며, 비정질 형성능 향상에 기여하 는 것으로 판단된다. 그림 7은 injection casting시 직경 2 $\mathrm{mm}$ 이상의 벌크 비정질 합금이 형성되는 영역을 유사 3 원 조성도(pseudo ternary composition diagram)에 나타내 었으며, 넓은 조성 영역에서 비정질이 형성되는 것을 보여 주고 있다.

그림 4에 나타낸 바와 같이 기계적인 강도도 기존에 보 고된 $\mathrm{Mg}-\mathrm{Cu}-\mathrm{Gd}$ 벌크 비정질 합금에 비해 약 $200 \mathrm{MPa}$ 정도의 높은 값을 나타내었다. $\mathrm{Mg}-\mathrm{Cu}-\mathrm{Gd}-\mathrm{Nd}$ 벌크 비정질 합금의 향상된 강도값은 구성 원자들 간의 원자 반경 차이 와 큰 음의 혼합열에 의한 구성 원자들 사이에는 강한 결 합력과 조밀한 원자 충진 배열(dense randomly packed atomic configurations)에 기인하는 것으로 판단된다 [17].

그림 6의 활성화 에너지 값으로부터 $\mathrm{Mg}-\mathrm{Nd}$ 모합금을 


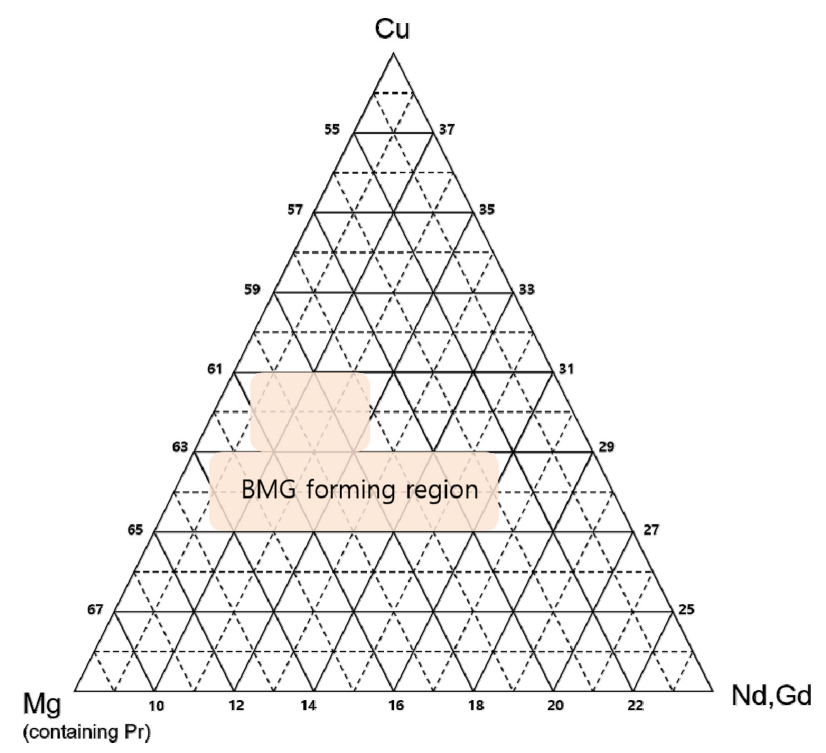

Fig. 7. Bulk metallic glass forming region in the pseudo ternary $\mathrm{Mg}-\mathrm{Cu}-(\mathrm{Nd}, \mathrm{Gd})$ system.

활용하여 제조된 비정질 합금은 순수한 원소만을 이용하여 제조된 동일한 조성의 벌크 비정질 합금과 유사한 열적 안 정성을 가지고 있음을 알 수 있다. 이러한 결과로부터 $\mathrm{NdFeB}$ 자석 스크랩의 순환소재화 과정에서 얻어진 $\mathrm{Mg}$ $\mathrm{Nd}$ 모합금을 활용한 $\mathrm{Mg}-\mathrm{Cu}-\mathrm{Gd}-\mathrm{Nd}$ 벌크 비정질 합금의 제조는 $\mathrm{NdFeB}$ 자석 스크랩의 순환소재화 및 이를 활용한 새로운 $\mathrm{Mg}$ 계 벌크 비정질 합금의 제조라는 측면에서 의미 가 있다고 할 수 있고, 특히 고가의 희토류를 포함하는 벌 크 비정질 합금의 경제성 있는 제조 공정에 적용될 수 있 을 것으로 판단된다. 또한 $\mathrm{Mg}$ 계 벌크 비정질 합금뿐만 아 니라 $\mathrm{Nd}, \mathrm{Gd}$ 등의 희토류를 포함하는 고강도 $\mathrm{Mg}$ 합금 제조 및 개발에도 적용될 수 있을 것으로 기대된다. 더 나 아가 그림 1 의 $\mathrm{Mg}$ 용탕을 이용한 $\mathrm{NdFeB}$ 자석 스크랩으 로부터 $\mathrm{Nd}$ 을 추출하는 공정의 모식도에 나타낸 것처럼, 고 액 분리 공정을 이용하여 $\mathrm{Fe}-\mathrm{B}$ 모합금을 얻을 수 있으며, 이러한 $\mathrm{Fe}-\mathrm{B}$ 모합금은 $\mathrm{Fe}$ 계 합금 제조에도 활용될 수 있 을 것으로 기대된다.

\section{5. 결 론}

1. 본 연구에서는 $\mathrm{NdFeB}$ 자석 스크랩의 순환 소재화 공 정에서 얻어지는 $\mathrm{Mg}-\mathrm{Nd}$ 합금을 이용하여 새로운 $\mathrm{Mg}-\mathrm{Cu}-$ $\mathrm{Gd}-\mathrm{Nd}$ 벌크 비정질 합금을 성공적으로 개발하였다.

2. 제조된 $\mathrm{Mg}_{66.5-\mathrm{x}} \mathrm{Cu}_{28.5} \mathrm{Gd}_{\mathrm{x}} \mathrm{Nd}_{5}(\mathrm{x}=8,10 \mathrm{at} \%)$ 벌크 비정 질 합금은 약 $850 \mathrm{MPa}$ 의 압축파단강도와 $1.8 \%$ 의 총 연
신율을 나타내었다.

3. $\mathrm{NdFeB}$ 자석 스크랩의 순환 소재화 공정에서 얻어지 는 $\mathrm{Mg}-\mathrm{Nd}$ 합금을 이용하여 제조된 $\mathrm{Mg}_{56.5} \mathrm{Cu}_{28.5} \mathrm{Gd}_{10} \mathrm{Nd}_{5}$ 벌크 비정질 합금은 순수한 원소만을 이용하여 제조된 동 일한 조성의 벌크 비정질 합금과 유사한 열적 안정성을 가 졌다.

4. $\mathrm{NdFeB}$ 자석 스크랩으로부터 얻어진 $\mathrm{Mg}-\mathrm{Nd}$ 모합금 을 활용한 $\mathrm{Mg}-\mathrm{Cu}-\mathrm{Gd}-\mathrm{Nd}$ 벌크 비정질 합금의 제조 방법 은 $\mathrm{Nd}, \mathrm{Gd}, \mathrm{Pr}$ 등의 희토류를 포함하는 $\mathrm{Mg}$ 계 벌크 비정 질 합금 및 고강도 $\mathrm{Mg}$ 합금의 제조에 활용될 수 있을 것 으로 기대된다.

\section{감사의 글}

이 논문은 2015년 공주대학교 학술연구지원사업의 연구 지원에 의하여 연구되었으며 이에 감사드립니다.

\section{REFERENCES}

1. J. H. Jo, J. Korea Soc. Waste Manag. 32, 500 (2015).

2. J. W. Lyman and G. R. Palmer, High Temp. Mater. Processes 11, 175 (1993).

3. T. Uda, Mater. Trans. JIM 43, 55 (2002).

4. M. Firdaus, M. A. Rhamdhani, Y. Durandet, W. J. Rankin, and K. McGregor, J. Sustain. Metall. 2, 276 (2016).

5. O. Takeda, T. H. Okabo, and Y. Umetsu, J. Alloy. Compd. 392, 206 (2005).

6. T. Okabe and Y. Umetsu, J. Alloy. Compd. 408-412, 387 (2006).

7. T. Akahori, Y. Miyamoto, T. Saeki, M. Okamoto, and T. H. Okabe, J. Alloy. Compd. 703, 337 (2017).

8. V. Raghavan, J. Phase Equilibria Diffus. 27, 292 (2006).

9. X. Jin, W. Xu, D. Shan, C. Lin, and Q. Zhang, Met. Mater. Int. 23, 434 (2017).

10. S. W. Nam, Korean J. Met. Mater. 55, 209 (2017).

11. A. R. Natarajan, E. L. S. Solomon, B. Puchala, E. A. Marquis, and A. Van der Ven, Acta Mater. 108, 367 (2016).

12. D. Choudhuril, N. Dendge, S. Nag, M. A. Gibson, and R. Baneriee, Metall. Mater. Trans. A 44, 2905 (2013).

13. Y. Li, H. Y. Liu, and H. Jones, J. Mater. Sci. 31, 1857 (1996).

14. Q. Zheng, H. Ma, E. Ma and J. Xu, Scripta Mater. 55, 541 (2006).

15. H. J. Chae, Y. D. Kim, B. S. Kim, J. G. Kim, and T. S. Kim, J. Alloy. Compd. 586, S143 (2014). 
16. M. Sun, X. Hu, L. Peng, P. Fu, W. Ding, and Y. Peng, J. Mater. Process Tech. 218, 57 (2015).

17. G. B. Liu, P. Gao, S. Q. Yang, Z. Xue, and M. L. Zhang, J. Alloy. Compd. 588, 59 (2014).

18. F. Spaepen, Acta Metall. 25, 407 (1977).
19. A. S. Argon, Acta Metall. 27, 47 (1979).

20. H. J. Lemeay, H. S. Chen, and T. T. Wang, Metall. Trans. 3, 699 (1972).

21. H. E. Kissinger, Anal. Chem. 291702 (1957).

22. A. Inoue, Acta Mater. 48, 279 (2000). 